\begin{tabular}{|c|c|c|}
\hline 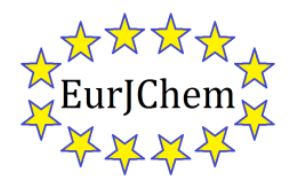 & $\begin{array}{c}\text { European Journal of Chemistry } \\
\text { Journal homepage: } \underline{\text { www.eurjchem.com }}\end{array}$ & 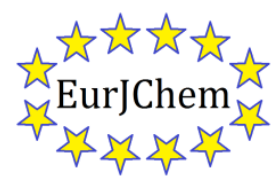 \\
\hline
\end{tabular}

\title{
Inhibitive action of Bridelia retusa leaves extract on corrosion of mild steel in acidic media
}

\author{
Niketan Patela ${ }^{a}$, , Anamika Rawat ${ }^{\mathrm{b}}$, Smita Jauharia and Girish Mehta ${ }^{\mathrm{a}}$ \\ a Department of Applied Chemistry, Sardar Vallabhbhai National Institute of Technology, Surat-395007, Gujarat, India \\ b Bhanuben and Ratilal Doshi School of Biosciences, Sardar Patel University, Vallabh Vidyanagar Nagar-388120, Gujarat, India \\ *Corresponding author at: Department of Applied Chemistry, Sardar Vallabhbhai National Institute of Technology, Surat-395007, Gujarat, India. \\ Tel.: +91-261-2201655; fax: +91-261-2201655. E-mail address: niketan.ptl@gmail.com (N. Patel).
}

\section{ARTICLE INFORMATION}

Received: 17 February 2010

Received in revised form: 27 April 2010

Accepted: 27 April 2010

Online: 30 June 2010

\section{KEYWORDS}

Bridelia retusa

Acid corrosion inhibitor

Electrochemical polarization

Electrochemical impedance spectroscopy

Scanning electron microscopy

Mild steel

\section{Introduction}

Large amount of $\mathrm{H}_{2} \mathrm{SO}_{4}$ is used in the chemical industry for removal of the undesired scales and rust. The addition of corrosion inhibitors effectively secures the metal against an acid attack. Many studies in this regard using organic inhibitors have been reported [1-3]. Most of these organic inhibitors with $\mathrm{N}, \mathrm{S}$ and $\mathrm{O}$ hetero-atoms have higher electron density making them the reaction centers. These compounds are adsorbed on the metallic surface and block the active corrosion sites and most of them are highly toxic to both human beings and environment. Hence use of the natural products as eco-friendly and harmless corrosion inhibitors, has become popular [4-7]. Comparison has been made over the years between the toxic inhibitors like chromates and other organic inhibitors with the natural inhibitors. It was observed that it could serve as an effective substitute for currently preferred organic inhibitors; sometimes they show significantly better inhibitive properties than currently employed organic corrosion inhibitors $[8,9]$.

Bridelia retusa (L.) Sprengel, a Euphorbiaceae family plant is found through out Asia and also in India, commonly known as Kasai. The plant is a shrub or a tree up to 18 meter in height armed with strong conical spines $7 \mathrm{~cm}$ long. The plant has been used in traditional systems of medicines for treatment of dysentery and diarrhea, diabetes [10]. However; B. retusa leaves have never been exploited as the corrosion inhibitor in acid medium. The aim of this work was to investigate the potential of the $B$. retusa leaves extract to act as an inhibitor of mild steel corrosion in sulphuric acid.

\section{Experimental}

\subsection{Inhibitor preparation}

About 25 grams of dried and powdered leaves of B. retusa was refluxed with $1 \mathrm{~N} \mathrm{H}_{2} \mathrm{SO}_{4}$ for about $5 \mathrm{~h}$ and was kept overnight to extract the basic components. The solution was filtered off and the filtrate was diluted to $500 \mathrm{~mL}$ with $1 \mathrm{~N}$ $\mathrm{H}_{2} \mathrm{SO}_{4}$. This extract was used to study the corrosion inhibition properties. To know the mass of plant extract, $100 \mathrm{~mL}$ of the extract is taken and is neutralized with $1 \mathrm{~N} \mathrm{NaOH}$ up to $\mathrm{pH}=8$ in order to liberate the base from the salt. The neutralized solution was then extracted with chloroform. The organic (chloroform) layer consisting of basic organic compounds was evaporated and the resultant gummy material obtained was dried and powdered. From the weight, mg of plant compounds in the extract is calculated. The aggressive acid solutions used were made of analytical reagent (AR) grade of $\mathrm{H}_{2} \mathrm{SO}_{4}$. The concentration range taken was varied from 25 to $200 \mathrm{ppm}$ in $1 \mathrm{~N} \mathrm{H}_{2} \mathrm{SO}_{4}$.

\subsection{Preparation of specimens}

Cylindrical working electrodes of mild steel (MS) containing $0.09 \% \mathrm{P}, 0.37 \% \mathrm{Si}, 0.01 \% \mathrm{Al}, 0.05 \% \mathrm{Mn}, 0.19 \% \mathrm{C}$, $0.06 \% \mathrm{~S}$ and the remainder $\mathrm{Fe}$, were used for the electrochemical polarizations and impedance measurements. The surface preparation of the mechanically polished specimens were carried out using different grades of emery papers, degreased with acetone dried at room temperature and then stored in a desiccator before use. 


\subsection{Weight loss method}

The polished and pre-weighed MS specimens were tied with threads and suspended in $100 \mathrm{~mL}$ test solutions, with and without the extracts of different concentrations, for $2 \mathrm{~h}$ of immersion at $303 \mathrm{~K}, 313 \mathrm{~K}$ and $323 \mathrm{~K}$. The temperature was controlled by an aqueous thermostat. After the corrosion test; the specimens were carefully washed in double-distilled water, dried and then weighed. The rinse removed loose segments of the film of the corroded samples. Duplicate experiments were performed in each case and the mean value of the weight loss is reported. The loss in weight was determined by analytic balance. The method has a low accuracy when the corrosion rate is low due to a longer test time. The corrosion rate obtained by this method is significant when the corrosion is uniform over the surface and not when there is an extensive localized corrosion. In the inhibited system only weight loss method may not be enough. From the weight loss data, percent inhibition efficiency (IE \%) was calculated.

\subsection{Electrochemical and impedance measurements}

A three-electrode cell of Borosilicate glass, consisting of a working electrode (WE) of MS, a pure platinum counter electrode (CE), and Saturated calomel electrode (SCE) as a reference electrode, was used for the measurements. The electrolytes used were in acidic solutions maintained at $30{ }^{\circ} \mathrm{C}$. The alternating current $(\mathrm{AC})$ impedance measurements are shown as Nyquist plots and polarization data as Tafel plots. $\mathrm{CH}$ Electrochemical analyzer model $608 \mathrm{C}$ (USA) was used for this purpose. Polarization resistance measurements were carried out with a scan rate of $0.01 \mathrm{~V} / \mathrm{s}$ at $-10 \mathrm{mV}$ to $+10 \mathrm{mV}$ vs. corrosion potential $\left(\mathrm{E}_{\mathrm{corr}}\right)$ of the working electrode measured against SCE. Polarization curves obtained again with the scan rate of $0.01 \mathrm{~V} / \mathrm{s}$ in the range of $-250 \mathrm{mV}$ to $+250 \mathrm{mV}$ vs. $E_{\text {corr. }}$. Impedance measurements were carried out at the $\mathrm{E}_{\text {corr }} ; 0 \mathrm{~min}$ after the electrode had been immersed in the test solution. The frequency range studied was $0.1 \mathrm{~Hz}$ to $1000 \mathrm{~Hz}$. The a.c. signal was $5 \mathrm{mV}$ peak-to-peak with 12 data points per decade.

\section{Results and Discussion}

Based on weight loss measurements, the corrosion rate $\left(\mathrm{W}_{\text {corr }}\right)$ and the values of inhibition efficiency $\left(\mathrm{E}_{\mathrm{w}} \%\right)$ for various concentrations of $B$. retusa leaves extract after $2 \mathrm{~h}$ of immersion at $303 \mathrm{~K}, 313 \mathrm{~K}$ and $323 \mathrm{~K}$ are given in Table 1 . The relation equation determines the inhibition efficiency:

$$
E_{W} \%=100 \times \frac{W_{0}-W_{\text {corr }}}{W_{0}}
$$

Where $\mathrm{W}_{\text {corr }}$ and $\mathrm{W}_{0}$ are the corrosion rates of steel with and without the inhibitor, respectively.

From the Table 1 it is clear that the $\mathrm{E}_{\mathrm{w}} \%$ increases with the increase of concentration reaching a maximum value of $91.6 \%$ at a higher concentration of $200 \mathrm{ppm}$ at $303 \mathrm{~K}$. This suggests that increase in the inhibitory concentration increases the number of molecules adsorbed over the mild steel surface, blocking the active sites of acid attack and thereby protecting the metal from corrosion. Generally the corrosion increases with the rise of temperature and that we can see from the Table 1.

The degree of surface coverage $\theta$ for different concentrations of the inhibitor in acidic media has been evaluated from weight loss using the equation:

$$
\theta=\frac{W_{0}-W_{\text {corr }}}{W_{0}}
$$

Table 1. Inhibition Efficiency of MS in $1 \mathrm{~N} \mathrm{H}_{2} \mathrm{SO}_{4}$ at various temperatures in the presence and absence of different concentrations of $B$. retusa leaves

\begin{tabular}{ccccc} 
extract. & & & & \\
\hline $\begin{array}{c}\text { Temperature } \\
(\mathbf{K})\end{array}$ & $\begin{array}{c}\text { Concentration } \\
\text { (ppm) }\end{array}$ & $\begin{array}{c}\mathbf{W} \\
\left(\mathbf{m g} / \mathbf{c m}^{2} \mathbf{h}\right)\end{array}$ & $\begin{array}{c}\text { Inhibition } \\
\text { Efficiency } \\
\mathbf{E}_{\mathbf{w}} \mathbf{\%}\end{array}$ & $\boldsymbol{\theta}$ \\
\hline & $1 \mathrm{~N} \mathrm{H}_{2} \mathrm{SO}_{4}$ & 18.34 & - & - \\
& 25 & 4.23 & 76.94 & 0.7694 \\
& 50 & 3.07 & 83.26 & 0.8326 \\
303 & 100 & 2.28 & 87.57 & 0.8757 \\
& 150 & 1.98 & 89.20 & 0.8920 \\
& 200 & 1.54 & 91.60 & 0.9160 \\
& $1 \mathrm{~N} \mathrm{H}_{2} \mathrm{SO}_{4}$ & 19.67 & - & - \\
& 25 & 5.37 & 72.70 & 0.7270 \\
313 & 50 & 3.82 & 80.58 & 0.8058 \\
& 100 & 3.18 & 83.83 & 0.8383 \\
& 150 & 2.58 & 86.88 & 0.8688 \\
& 200 & 2.26 & 88.51 & 0.8851 \\
& $1 \mathrm{~N} \mathrm{H}_{2} \mathrm{SO}_{4}$ & 20.69 & - & - \\
& 25 & 5.96 & 71.19 & 0.7119 \\
323 & 50 & 4.40 & 78.73 & 0.7873 \\
& 100 & 3.88 & 81.24 & 0.8124 \\
& 150 & 3.17 & 84.68 & 0.8468 \\
& 200 & 2.86 & 86.18 & 0.8618 \\
\hline
\end{tabular}

From Table 1 , the increase of $\mathrm{W}_{0}$ is more pronounced with the rise of temperature for the blank solution. In the presence of $B$. retusa leaves extract $\theta$ decreases slightly with increasing experimental temperature, which could be caused by, desorption of the inhibitor from the steel surface. The slight decrease of $\theta$ suggests that the efficiency of $B$. retusa leaves extract is independent of temperature. The result shows that $B$. retusa leaves extract effectively protects the steel even at high temperature.

The adsorption of the inhibitor is influenced by the nature and the charge of the metal, the chemical structure of the inhibitor, distribution of the charge in the molecule, and the type of electrolyte [11-13]. Important information about the interaction between the inhibitor and steel surface can be obtained by the adsorption isotherm. In the present work, it could be concluded that $\theta$ increases with the inhibitor concentration; this is attributed to more adsorption of $B$. retusa onto the steel surface. Now, assuming that the adsorption of $B$. retusa leaves extract belonged to the monolayer adsorption, then the Langmuir adsorption isotherm is applied to investigate the mechanism by the following equation:

$\frac{C}{\theta}=\frac{1}{K}+C$

Where $\mathrm{C}$ is the inhibitor concentration in the electrolyte and $\mathrm{K}$ is the equilibrium constant for the adsorption/desorption process.

Three representative Langmuir adsorption plots at different temperatures are shown in Figure 1. Linear plots are obtained with slopes equal to $1.06,1.09$ and 1.12 for the experimental temperature at 303,313 and $323 \mathrm{~K}$, respectively. These results indicate that some constituent of $B$. retusa leaves unit occupies more than one adsorption site on the steel surface. A modified Langmuir adsorption isotherm [14,15] could be applied to this phenomenon, which is given by the corrected equation:

$$
\frac{C}{\theta}=\frac{n}{K}+n C
$$

Where $n$ is the value of slopes obtained by above plot, The Langmuir isotherm, originally derived for the adsorption of gas molecules on solid surfaces, was modified to fit the adsorption isotherm of solutes onto solid surfaces in solution. The aim of this modification was based on the fact that direct application of the Langmuir isotherm to solution systems often leads to poor data fitting [14]. 


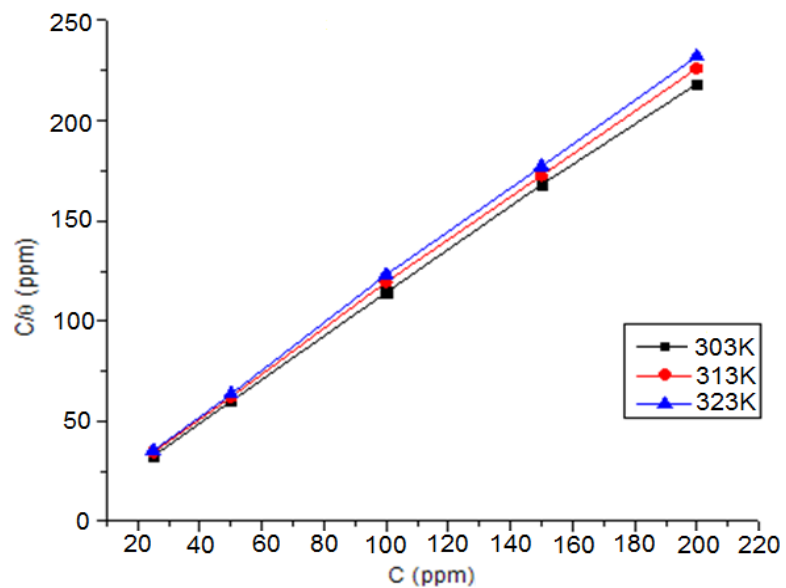

Figure 1. Langmuir adsorption plots for mild steel in $1 \mathrm{~N} \mathrm{H}_{2} \mathrm{SO}_{4}$ at different temperatures.

The potentiodynamic polarization data are shown as the Tafel plots for MS in $1 \mathrm{~N} \mathrm{H}_{2} \mathrm{SO}_{4}$ with the addition of various concentrations of the additive in Figure 2. The corrosion kinetic parameters such as corrosion potential $\left(\mathrm{E}_{\text {corr }}\right)$, corrosion current density ( $\mathrm{I}_{\text {corr }}$ ), anodic and cathodic Tafel slopes $\left(\mathrm{b}_{\mathrm{a}}\right.$ and $b_{c}$ ) were derived from these curves and are given in Table 2 . The values of the Inhibition Efficiency $E_{1} \%$ are calculated using the following equation.

$E_{I} \%=100 \times \frac{I_{\text {corr }}-I_{\text {corr }(\mathrm{inh})}}{I_{\text {corr }}}$

Where Icorr and Icorr(inh) are the values of corrosion current densities of MS without and with the additive, respectively, which were determined by extrapolation of the cathodic and anodic Tafel lines to the corrosion potential $\mathrm{E}_{\text {corr. }}$.

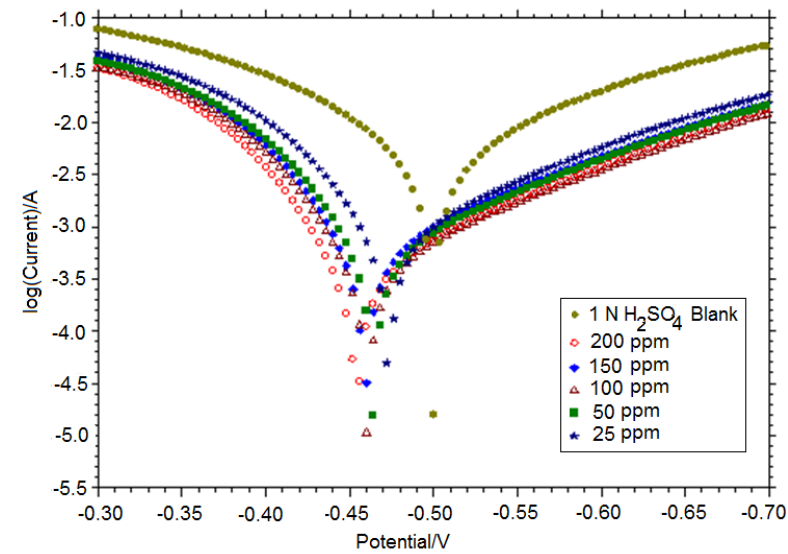

Figure 2. Tafel plots showing effect of $B$. retusa leaves extracts on corrosion of MS in $\mathrm{H}_{2} \mathrm{SO}_{4}$ medium.

The inhibiting properties of the extract have also been evaluated by the determination of the polarisation resistance. The corresponding polarisation resistance $\left(R_{p}\right)$ values of MS in $1 \mathrm{~N} \mathrm{H}_{2} \mathrm{SO}_{4}$ in the absence and presence of different concentrations of the $B$. retusa leaves extracts are given in Table 2. The inhibition efficiency ( $\left.E_{R p} \%\right)$ was defined as follows:

$E_{R p} \%=100 \times \frac{R_{P(i n h)}-R_{P}}{R_{P(i n h)}}$
$\mathrm{R}_{\mathrm{p}}$ and $\mathrm{R}_{\mathrm{p}(\mathrm{inh})}$ are the polarisation resistance in the absence and in the presence of the inhibitor, respectively.

From the Table 2, it is observed that the $I_{\text {corr }}$ values gradually decreased with concomitant increase in the concentration of additive up to $200 \mathrm{ppm}$ from 5.914 to 0.518 $\mathrm{mA} / \mathrm{cm}^{2}$ leading to $91 \%$ of IE. Further, there was anodic shift of the $E_{\text {corr value of }}-0.5 \mathrm{~V}$ (blank) to $-0.45 \mathrm{~V}$ at $200 \mathrm{ppm}$ indicating that the $B$. retusa leaves extracts acted as an anodic inhibitor [16] for MS in $1 \mathrm{~N} \mathrm{H}_{2} \mathrm{SO}_{4}$ which was supported by the gradual and significant decrease of anodic Tafel slope, $b_{a}$ is 143 $\mathrm{mV} /$ decade of blank to $91 \mathrm{mV} /$ decade at $200 \mathrm{ppm}$. It could be derived from this decrease that the rate of anodic dissolution was much retarded in comparison to that of cathodic hydrogen evolution. There was decrease of only $14 \mathrm{mV}$ in the corresponding values of cathodic Tafel slopes. This means that the extract must have acted predominantly by blocking anodic sites, and also cathodic sites to some extent, and the extract contained the active molecules which behaved as mixed-type of the acid corrosion inhibitors.

The $\mathrm{Rp}_{\mathrm{p}}$ values of MS in $1 \mathrm{~N} \mathrm{H}_{2} \mathrm{SO}_{4}$ in the absence and presence of different concentrations of the tested inhibitor are also given in Table 2 . From the results, $\mathrm{R}_{\mathrm{p}}$ values gradually increased with increase in the concentration of inhibitor and $\mathrm{E}_{\mathrm{Rp}} \%$ increases to attain $88 \%$ at $100 \mathrm{ppm}$. The values of inhibition efficiency of $B$. retusa leaves extract obtained by electrochemical methods are in good agreement.

The corrosion behavior of MS in $1 \mathrm{~N} \mathrm{H}_{2} \mathrm{SO}_{4}$, in absence and the presence of various concentrations of $B$. retusa leaves extract were also investigated by Electrochemical Impedance Spectroscopy (EIS) technique. The resultant Nyquist plots are shown in Figure 3. The existence of a single semicircle in each plot shows that there was only single charge transfer process during the anodic dissolution of MS and remained unaffected in the presence of inhibitive molecules of the extract added in the acid. An isolated Nyquist plot for the blank system is shown in the window in Figure 3. The value of real impedance ( $Z^{\prime}$ ) was only $7 \mathrm{ohms}$, indicates that there was least charge transfer resistance $\left(R_{t}\right)$ of the corrosion reactions. There was gradual increase in the diameter of each semicircle of the Nyquist plot due to increase in the number of inhibitive molecules in the extract when the concentration was raised from 25 to $200 \mathrm{ppm}$. This increase of the diameters was clearly reflected in that the $\mathrm{R}_{\mathrm{t}}$ values also increased from 7 to 237 ohms at highest concentration of $200 \mathrm{ppm}$ due to formation and gradual improvement of the barrier layer of the inhibitive molecules (IE $97 \%$ ), and as a result the acid corrosion rate of MS gradually decreased. All the results obtained are accurate and if the experiments are carried out under given set of conditions it gives reproducible results.

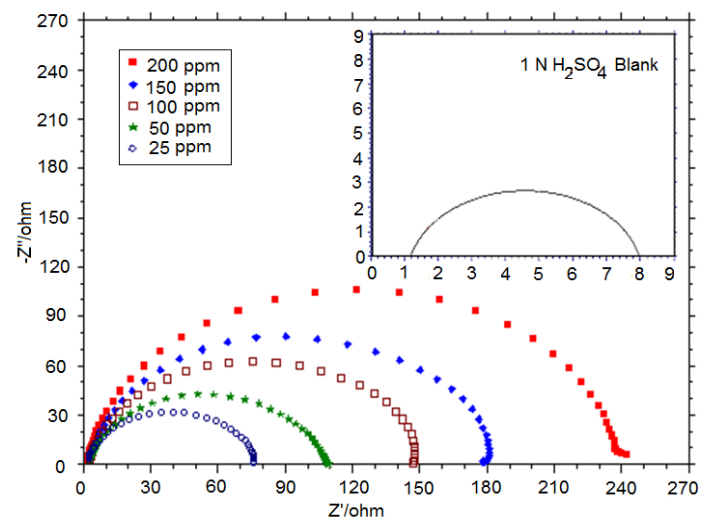

Figure 3. Nyquist plots showing effect of $B$. retusa leaves extracts on corrosion of MS in $\mathrm{H}_{2} \mathrm{SO}_{4}$ medium. 
Table 2. Effect of B. retusa leaves extracts on MS in 1N H2SO4 media (Electrochemical polarizations studies).

\begin{tabular}{|c|c|c|c|c|c|c|c|}
\hline \multirow{2}{*}{$\begin{array}{l}\text { Concentration of inhibitor, } \\
\text { (ppm) }\end{array}$} & \multirow[t]{2}{*}{$\mathbf{E}_{\text {corr },} \mathbf{V}$} & \multicolumn{2}{|c|}{$\begin{array}{l}\text { Tafel Constant, } \\
\text { (mV/decade) }\end{array}$} & \multirow[t]{2}{*}{$I_{\text {corr, }}\left(\mathbf{m A} / \mathbf{c m}^{2}\right)$} & \multirow{2}{*}{ 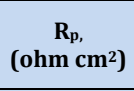 } & \multirow[t]{2}{*}{$E_{1}, \%$} & \multirow[t]{2}{*}{$\mathbf{E}_{\mathrm{Rp}} \%, \%$} \\
\hline & & ba & Bc & & & & \\
\hline 0 & -0.4997 & 143 & 160 & 5.914 & 06 & - & - \\
\hline 25 & -0.4732 & 107 & 149 & 1.260 & 22 & 78.7 & 72.7 \\
\hline 50 & -0.4644 & 102 & 151 & 0.884 & 30 & 85.1 & 80.0 \\
\hline 100 & -0.4600 & 95 & 150 & 0.618 & 41 & 89.6 & 85.4 \\
\hline 150 & -0.4591 & 96 & 150 & 0.610 & 43 & 89.7 & 86.0 \\
\hline 200 & -0.4538 & 91 & 146 & 0.518 & 48 & 91.2 & 87.5 \\
\hline
\end{tabular}

Table 3 embodies various parameters such as $\mathrm{R}_{\mathrm{t}}$ and double layer capacitance $\left(\mathrm{C}_{\mathrm{dl}}\right)$. There was a gradual decrease in values of $\mathrm{C}_{\mathrm{dl}}$ from 155 to $66 \mu \mathrm{F} / \mathrm{cm}^{2}$ with increase in the concentration of the extract. This considerable change indicated that the inhibitive molecules of the extracts have been adsorbed on the MS surface and decreased the roughness of the MS surface. The values of $\mathrm{E}_{\mathrm{R}} \%$ were calculated by the equation as follows.

$E_{R} \%=100 \times \frac{R_{t(i n h)}-R_{t}}{R_{t(i n h)}}$

Where $\mathrm{R}_{\mathrm{t}}$ and $\mathrm{R}_{\mathrm{t}(\mathrm{inh})}$ are the charge-transfer resistance values in absence and the presence of the extracts, respectively.

Table 3. Data from electrochemical impedance measurements of mild steel in $1 \mathrm{~N} \mathrm{H}_{2} \mathrm{SO}_{4}$ at $30{ }^{\circ} \mathrm{C}$ for various concentrations of B. retusa leaves extract.

\begin{tabular}{cccc}
\hline $\begin{array}{c}\text { Concentration of } \\
\text { inhibitor, }(\mathbf{p p m})\end{array}$ & $\begin{array}{c}\mathbf{R}_{\mathbf{t}}, \\
\mathbf{O h m . c m}^{2}\end{array}$ & $\begin{array}{c}\mathbf{C d l}, \\
\boldsymbol{\mu} \mathbf{F} / \mathbf{c m}^{\mathbf{2}}\end{array}$ & $\begin{array}{c}\text { Inhibition } \\
\text { Efficiency, } \mathbf{E}_{\mathbf{R}} \mathbf{\%}\end{array}$ \\
\hline 0 & 07 & 155.27 & - \\
25 & 77 & 90.91 & 90.9 \\
50 & 108 & 85.23 & 93.5 \\
100 & 150 & 75.69 & 95.3 \\
150 & 184 & 69.86 & 96.2 \\
200 & 237 & 65.65 & 97.0 \\
\hline
\end{tabular}

To obtain the values of $C_{d 1}$, the values of frequency $\left(f_{\max }\right)$ at which the imaginary component of the impedance is maximum $-Z_{i m(\max )}$ was found and used in the following equation with corresponding $\mathrm{R}_{\mathrm{t}}$ values:

$$
C_{d l}=\frac{1}{2 \pi f_{\max } R_{t}}
$$

The SEM photograph in Figure 4a shows that the surface of MS was extremely damaged in the absence of the extract while Figure $4 \mathrm{~b}$ shows the formation of a film by the active $B$. retusa leaves constituents on the MS surface which was responsible for the corrosion inhibition.

The inhibition properties of $B$. retusa leaves extract may be due to the adsorption of nitrogenous compounds in the extract or tannins on the MS surface present in the extract [17]. However, tannins are complex astringent aromatic acidic glycosides found in various plants and their presence can be ruled out as they are made up of the polyphenols and their acidic and heterocyclic derivatives, because such constituents would not have been extracted in the acid. Polar organic compounds containing $\mathrm{N}, \mathrm{S}$ and $\mathrm{O}$ are good corrosion inhibitors [18]. These may have been responsible for the formation of an oriented film layer by the adsorption of the active constituents of the extract on the MS surface, which essentially blocks discharge of $\mathrm{H}^{+}$and dissolution of metal ions. Acid pickling inhibitors containing organic molecules with $\mathrm{N}, \mathrm{S}$ and $\mathrm{OH}$ groups behave similarly to inhibit corrosion.

\section{Conclusions}

- The active molecules present in the extract of $B$. retusa leaves effectively inhibited the corrosion of mild steel in $1 \mathrm{~N} \mathrm{H}_{2} \mathrm{SO}_{4}$ at various temperatures by forming a protective barrier layer. It adsorbs on the steel surface according to the modified Langmuir adsorption isotherm. The inhibition efficiency of the extract increased gradually with increase in its concentration.

- Polarization measurements have shown that the extract of $B$. retusa leaves acted as a mixed-inhibitor, retarding predominantly anodic dissolution of steel in $1 \mathrm{~N} \mathrm{H}_{2} \mathrm{SO}_{4}$.

- The results of the weight loss, electrochemical polarization and AC impedance spectroscopy were all in very good agreement to support the above conclusions. Photographs by SEM have clearly shown the formation of the protective film on the surface of mild steel.

- $\quad$ The acid extract of B. retusa leaves can be considered as a source of relatively cheap, eco-friendly and effective acid corrosion inhibitors.

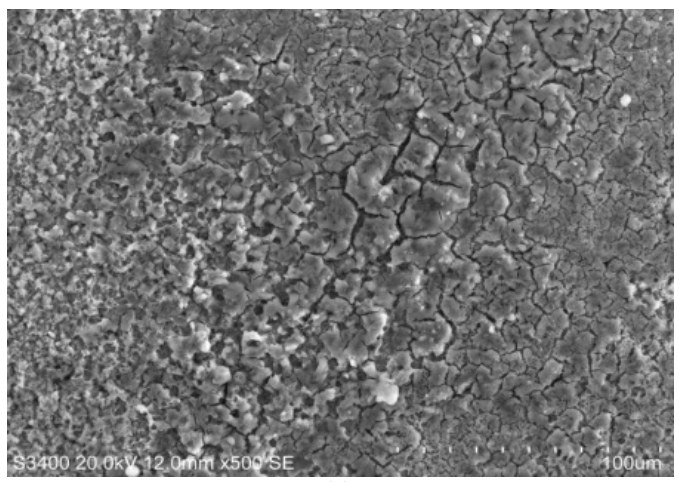

(a)

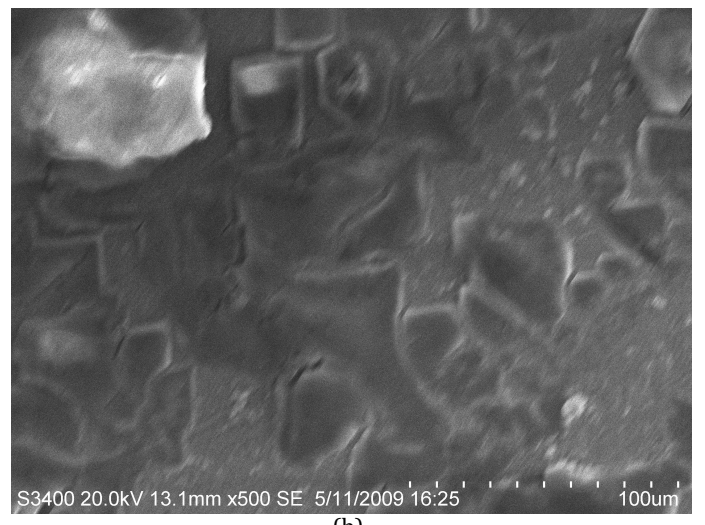

(b)

Figure 4. SEM images of MS a) in $1 \mathrm{~N} \mathrm{H}_{2} \mathrm{SO}_{4}$ media and b) with $B$. retusa leaves extract ( $200 \mathrm{ppm})$.

\section{Acknowledgements}

The authors thank Dr. P.D. Porey, Director and Dr. S. Jauhari, Head of Applied Chemistry Department of Sardar Vallabhbhai National Institute of Technology, Surat for the scholarship, encouragement and facilities. 


\section{References}

[1]. Tebbji, K.; Bouabdellah, I.; Aouniti, A.; Hammouti, B.; Oudda, H.; Benkaddour, M.; Ramdani, A. Mater. Lett. 2007, 61, 799-804.

[2]. Prabhu, R. A.; Shanbhag, A. V.; Venkatesha, T. V. J. Appl. Electrochem. 2007, 37, 491-497.

[3]. Avci, G. Colloids and Surfaces A: Physicochem. Eng. Asp. 2008, 317, 730736.

[4]. BothiRaja, P; Sethuraman, M. G. Mater. Lett. 2008, 62, 2977-2979.

[5]. De Souza, F. S; Spinelli, A. Corros. Sci. 2009, 51, 642-649.

[6]. Abdel-Gaber, A. M.; Khamis, E.; Abo-ElDahab, H; Adeel, S. Mater. Chem. Phys. 2008, 109, 297-305.

[7]. El Etre, A. Y.; El Tantawy, Z. Port. Electrochim. Acta 2006, 24, 347-356.

[8]. Blajiev, O.; Hubin, A. Electrochim. Acta 2004, 49, 2761-2770.

[9]. Valek, L.; Martinez, S. Mater. Lett. 2007, 61, 148-151.

[10]. Ngueyem, T. A.; Brusotti, G.; Caccialanza, G.; Finzi, P. J. Ethnopharmacol. 2009, 124, 339-349.

[11]. Rozenfeld, I. L., Corrosion Inhibitors, McGraw-Hill Inc., New York, 1981.

[12]. Popova, A.; Sokolova, E.; Raicheva, S.; Christov, M. Corros. Sci. 2003, 45, 33-58.

[13]. Zhang, D.; Gao, L.; Zhou, G.; Lee, K. J. Appl. Electrochem. 2008, 38, 71-76.

[14]. Villamil, R. F. V.; Corio, P.; Rubin, J.C.; Agostinho, S. M. L. J. Electroanal. Chem. 2002, 535, 75-83.

[15]. Villamil, R. F. V.; Corio, P.; Rubin, J.C.; Agostinho, S. M. L. J. Electroanal. Chem. 1999, 472, 112-119.

[16]. Riggs J. O. L. Corrosion Inhibitors, NACE Houston, USA, 1973.

[17]. Ekpe, U. J.; Ebenso, E. E.; Ibok, U. J. J. West African Assoc. 1994, 37, 1316.

[18]. Finley, H. F.; Hackerman, N.C. Ind. Eng. Chem.1960, 46, 523-530. 